\title{
What are the practical implications of developments in genetics?
}

\author{
E Pearson \\ Clinical Senior Lecturer, Biomedical Research Institute, University of Dundee, UK
}

\begin{abstract}
In recent years there has been a rapid increase in our understanding of the genetics of diabetes and the implication of genetics for clinical care. The major clinical breakthrough has been in identifying monogenic forms of diabetes. It has now been established that knowing the genetic aetiology alters treatment. This is seen for maturity onset diabetes of the young (MODY) caused by mutations in the HNFI $\alpha$ and HNF4 $\alpha$ genes (extreme sensitivity to sulphonylureas); mutations in the glucokinase gene (no treatment required); and for mutations in the potassium channel genes encoding Kir6.2 and SURI, where patients with neonatal diabetes can be transferred off insulin with high-dose sulphonylurea treatment. For the more common types of diabetes the clinical impact of genetics has yet to be realised, yet with the dramatic improvements in genotyping/sequencing technologies available it is probably just a matter of time before genetic profiling will be used to predict diabetes risk, or to tailor therapy for the individual.
\end{abstract}

Correspondence to E Pearson, Biomedical Research Institute, University of Dundee, Dundee DDI 9SY, UK

e.pearson@cpse.dundee.ac.uk doi:10.4997/JRCPE.2010.S02

DECLARATION OF INTERESTS No conflict of interests declared.

For many years the classical division of diabetes mellitus into type I and type 2 diabetes has served clinicians well. Those, usually young people, with an acute presentation had type I diabetes and required insulin. Those, usually older obese people, that did not have type I diabetes had type 2 diabetes. There were a few rare forms of diabetes known about, but it made no difference to treatment so these were rarely looked for.

The recent developments in the genetics of diabetes have provided considerable insight into the heterogeneity of diabetes, as well as the biology of $\beta$-cell dysfunction and insulin action. Initial advances were seen in 'monogenic diabetes', in which a single genetic defect causes diabetes, and it is these forms where there has been direct impact on clinical care and establishing the need for genetic testing in the diabetes clinic. More recently, there has been exponential progress in teasing out the genetics of complex type I and 2 diabetes. While this has revealed previously unconsidered pathways associated with diabetes, the potential clinical use of these findings has yet to be established. Therefore this review will focus primarily on monogenic diabetes, with just a brief overview of the developments in common types of diabetes.

\section{NEONATAL DIABETES}

Diabetes that presents before the age of six months is unlikely to be type I diabetes. ${ }^{1-2}$ Infants with neonatal diabetes mellitus (NDM) have low birth weight due to low fetal insulin secretion, and usually develop insulin requiring diabetes in the first three months of life. Presentation is often with severe hyperglycaemia or diabetic ketoacidosis. Clinically, neonatal diabetes can be divided into whether the diabetes persists (permanent, PNDM, 45\%) or resolves (transient, TNDM, $45 \%$ ). ${ }^{3}$ This clinical classification has been dissected by recent genetic developments. Transient NDM can now be almost entirely explained either by imprinting anomalies on chromosomal region $6 \mathrm{q} 24$, with the remainder due to $\mathrm{K}_{\text {ATP }}$ gene mutations. ${ }^{4}$ Approximately $60 \%$ of PNDM can be explained, primarily by mutations in the $\mathrm{K}_{\mathrm{ATP}}$ genes, but also by mutations in the insulin gene and homozygous mutations in glucokinase..$^{5-7}$ This review will focus on the $K_{\text {ATP }}$ channel. (For a review of all NDM please refer to Shield. ${ }^{8}$ )

\section{$K_{\text {ATP }}$ channel mutations}

The pancreatic $\beta$-cell secretes insulin in response to a variety of nutrient and other stimuli. The ATP-sensitive potassium $\left(K_{\text {ATP }}\right)$ channel is a key step in this process of stimulussecretion coupling, and consists of four Kir6.2 subunits (encoded by the $K C N I I I$ gene) and four SURI subunits (encoded by the $A B C C 8$ gene). Inactivating mutations cause the channel to be closed and thus the $\beta$-cells to over-secrete insulin, causing hyperinsulinaemic hypoglycaemia. ${ }^{9}$ Activating mutations cause the $\beta$-cell to be unresponsive to glucose and therefore are a cause of NDM. . $^{6-10-11}$

\section{Activating $K_{\text {ATP }}$ channel mutations cause PNDM, TNDM and neurological features}

The phenotype seen with mutations in SURI and Kir6.2 is very similar. Some mutations cause TNDM and the diabetes remits at 35 weeks (range 2-208 weeks) and then relapses at five years of age (range $\mathrm{I}-16$ years). ${ }^{4}$ Different mutations cause PNDM. About $20 \%$ of Kir6. 2 mutations are associated with neurological features due to the expression of the $\mathrm{K}_{\text {ATP }}$ channel in the brain, peripheral nerves and muscle. Approximately $5 \%$ have a neurological syndrome that is characterised by severe Developmental delay, Epilepsy and Neonatal Diabetes (DEND). About $15 \%$ have an intermediate phenotype 
(intermediate DEND or iDEND) with milder developmental delay and without epilepsy. ${ }^{6}$ Due to the severity of presentation, often with diabetic ketoacidosis (DKA), and the fact that the majority have no detectable endogenous insulin secretion, ${ }^{6,12}$ all patients with NDM, until recently, were initiated on insulin and those with PNDM remained insulin treated for life.

\section{Insulin can be replaced by oral sulphonylureas in patients with NDM}

The activating mutations in the $\mathrm{K}_{\text {ATP }}$ channel genes alter ATP sensitivity or gating of the channel, resulting in a lack of channel closure with a glucose stimulus. ${ }^{6}$ Sulphonylureas are a drug class that has been used for more than 50 years to treat type 2 diabetes. These drugs act on the SURI subunit of the $K_{\text {ATP }}$ channel to bring about channel closure. When three patients with Kir6.2 mutations were challenged with the intravenous sulphonylurea tolbutamide they produced measurable insulin secretion. ${ }^{6}$ This paved the way to conversion off insulin to oral sulphonylurea therapy, first in one case ${ }^{13}$ and then in a large series. ${ }^{12}$ In this series, $90 \%$ of patients were able to transition from insulin to sulphonylurea, and every individual who did so improved their glycaemic control (Figure I) (evidence level 2++).

Over and above the ability to transfer off insulin, what is striking about the glucose control in patients with PNDM treated with sulphonylureas is their near normoglycaemia and minimal hypoglycaemia.This reflects prandial regulation of insulin secretion, an effect that is mediated by sulphonylureas enabling the $\beta$-cell to respond to incretins. ${ }^{12}$ For many patients who have successfully transferred to sulphonylureas, they have normal glycosylated haemoglobin $\left(\mathrm{HbA}_{\mathrm{lc}}\right)$, can eat what they want, can do what they want and in essence are non-diabetic.

\section{MATURITY ONSET DIABETES OF THE YOUNG}

Maturity onset diabetes of the young (MODY) is noninsulin-requiring diabetes that presents in children or young adults and accounts for about $\mathrm{I}-2 \%$ of diabetes. It has an autosomal dominant inheritance and hence there is often a strong family history of diabetes. Once again, genetics has divided a clinically defined condition into a number of aetiologically distinct subtypes. The most clinically relevant of these will be discussed. These are MODY due to mutations in the transcription factors hepatocyte nuclear factor (HNF) I $\alpha, \mathrm{HNF} 4 \alpha$ and HNFI $\beta$; and the glycolytic enzyme glucokinase (reviewed in Stride and Hattersley ${ }^{14}$ ). The diabetes phenotype due to the transcription factor gene mutations is similar, with onset usually in adolescence or early adulthood, gradual progression requiring increasing treatment and ultimately insulin, and association with micro- and macrovascular complications. Glucokinase mutations, as will be discussed, cause stable, mild, non-progressive hyperglycaemia and are therefore quite distinct from the other MODY

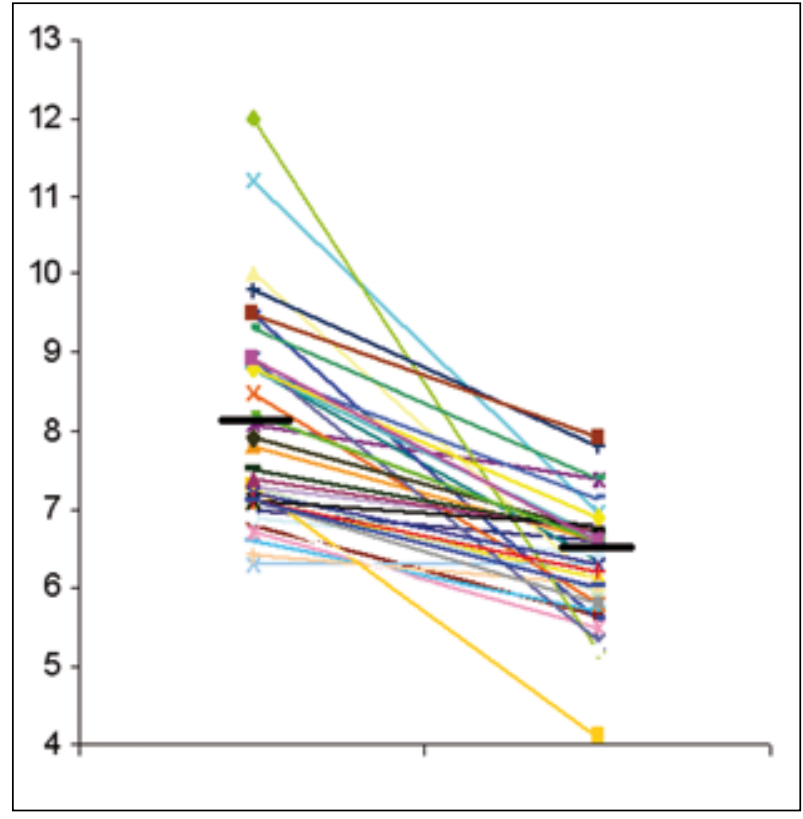

FIGURE I $\mathrm{HbA}_{\mathrm{lc}}$ prior to and after successful transfer off insulin onto sulphonylureas in patients with neonatal diabetes due to Kir6.2 mutations. ${ }^{12}$ (With kind permission of The New England Journal of Medicine.)

subtypes. Table I outlines the key features of the different MODY subtypes.

MODY due to HNFI $\alpha$ and HNF4 $\alpha$ mutations are sensitive to sulphonylureas and can transfer off insulin

A series of case reports ${ }^{15-17}$ prompted a randomised open-label crossover trial of metformin and sulphonylureas in patients with diabetes due to an HNFI $\alpha$ mutation and patients with type 2 diabetes matched for age and body mass index (BMI). ${ }^{18}$ Treatment consisted of gliclazide for six weeks, followed by metformin for six weeks (or vice versa). The primary outcome was fasting glucose reduction from baseline. The results of this study showed dramatically greater response to sulphonylureas in patients with HNFI $\alpha$ mutations compared to their response to metformin and compared to response to gliclazide in patients with type 2 diabetes (Figure 2) (evidence level I+). The mechanism for this sensitivity reflects the fact that sulphonylureas act downstream of the major defects seen with $\mathrm{HNFI} \alpha$ mutations so a patient with an HNFI $\alpha$ mutation is essentially blind to glucose but sensitive to sulphonylureas. Although there are no such robust data for patients with HNF4 $\alpha$ similar sulphonylurea sensitivity has been described ${ }^{19}$ (evidence level 3 ).

Because of the marked sensitivity to sulphonylureas in HNFI $\alpha$ diabetes, patients who had been misdiagnosed as having type I diabetes and were insulin treated, but who subsequently were found to have an HNFI $\alpha$ mutation were trialled with sulphonylureas. ${ }^{20}$ All 34 patients successfully transferred off insulin, some with 
TABLE I Features of the MODY subtypes (adapted from Hattersley A et al. ${ }^{39}$ )

\begin{tabular}{|c|c|c|c|}
\hline & Age of onset (range) & Diabetes characteristics & Other features \\
\hline $\begin{array}{l}\text { HNFI } \alpha \\
\text { (MODY 3) }\end{array}$ & $14(4-18)$ & $\begin{array}{ll}\text { - } & \text { Progressive } \\
\text { - } & \text { Sulphonylurea sensitivity }\end{array}$ & $\begin{array}{l}\text { - Low renal threshold for glucose } \\
\text { - Normal birthweight }\end{array}$ \\
\hline $\begin{array}{l}\text { HNF4 } \alpha \\
\text { (MODY 4) }\end{array}$ & $17(5-18)$ & $\begin{array}{ll}- & \text { Progressive (like HNFI } \alpha \text { ) } \\
\text { - } & \text { Sulphonylurea sensitivity } \\
\end{array}$ & $\begin{array}{ll}\text { - } & \text { Hyperinsulinaemic hypoglycaemia } \\
\text { - } & \text { Macrosomia and increased birth weight }\end{array}$ \\
\hline $\begin{array}{l}\text { HNFI } \beta \\
\text { (MODY 5) }\end{array}$ & $26(|0-6|)$ & $\begin{array}{ll}\text { - } & \text { Diabetes only present in } 50 \% \\
\text { of mutation carriers } \\
\text { - } \quad \text { Rapidly progresses to insulin } \\
\text { - } \\
\quad \beta \text {-cell dysulin resistance as well as } \\
\end{array}$ & $\begin{array}{ll}\text { - } & \text { Low birth weight } \\
\text { - } & \text { Renal cysts } \\
\text { - } & \text { Genital tract malformation } \\
\text { - } & \text { Hyperuricaemia } \\
\text { - } & \text { Elevated alanine aminotransferase } \\
\text { - } & \text { Pancreatic exocrine dysfunction } \\
\text { - } & \text { Absent pancreatic body and tail }\end{array}$ \\
\hline $\begin{array}{l}\text { GCK } \\
\text { (MODY 2) }\end{array}$ & $\begin{array}{l}\text { When tested (present } \\
\text { from birth) }\end{array}$ & $\begin{array}{l}\text { Stable non-progressive fasting } \\
\text { hyperglycaemia }\end{array}$ & $\begin{array}{l}\text { - Fasting glucose } 5.5-8 \mathrm{mmol} / \mathrm{l} \\
\text { - Small increment at oral glucose tolerance } \\
\text { test }(2 \text { hours increment }<3.5 \mathrm{mmol} / \mathrm{l})\end{array}$ \\
\hline
\end{tabular}

over 30 years of being 'insulin-dependent' (evidence level $2+)$. However, 10 patients subsequently had insulin reintroduced. The 24 remaining off insulin remained off for between 17 and 90 months; of these $80 \%$ achieved an $\mathrm{HbA}_{\mathrm{Ic}}$ of $<7.5 \%$ or a $>1 \%$ reduction. ${ }^{20}$

The decision to be made clinically when treating nontype I diabetes is what oral agent to prescribe. In type 2 diabetes, metformin and sulphonylureas have similar efficacy, ${ }^{21}$ but metformin is usually favoured because of its macrovascular benefit and weight neutrality. However, if a patient is known to have an HNFI $\alpha$ mutation, even if they are phenotypically indistinct from someone with type 2 diabetes, the randomised trial ${ }^{18}$ would support the use of sulphonylureas as first-line agent in this patient group (A grade), as $62 \%$ responded at least twofold better to gliclazide than they did to metformin. This contrasts with just $16 \%$ in those with type 2 diabetes. In addition, knowing someone has an $\mathrm{HNFI} \alpha$ mutation should prompt an attempt at transfer off insulin to sulphonylureas in patients who have not previously failed on a sulphonylurea ( $C$ grade). This is the first robust evidence for genetics impacting on the clinical therapeutic management of diabetes.

HNF4 $\alpha$ mutations cause macrosomia and neonatal hyperinsulinaemic hypoglycaemia

Although the diabetes phenotype due to HNF4 $\alpha$ mutations is similar to that due to HNFI $\alpha$ mutations, HNF4 $\alpha$ mutations cause hyperinsulinaemia in utero, and in some this also manifests as hyperinsulinaemic hypoglycaemia in the neonatal period ${ }^{22}$ (evidence level $2+)$. In the UK series, the affected offspring birth weight was $790 \mathrm{~g}$ heavier than the unaffected (no HNF4 $\alpha$ mutation) offspring, and as a result there was greater extreme macrosomia ( $>5 \mathrm{~kg}$ birth weight) and two cases of Erb's palsy or shoulder dystocia. ${ }^{22}$ Transient hypoglycaemia was reported in $8 / 54$ infants with heterozygous $\mathrm{HNF} 4 \alpha$ mutations, but was reported in none of 54 non-mutation carriers $(p<0.003)$. There was documented hyperinsulinaemia in three cases. The hypoglycaemia was diazoxide responsive and resolved in all cases by one year of age. The mechanism for this paradoxical oversecretion in utero, and subsequent hypoinsulinaemia causing diabetes in later life has still to be explained. However, clinically, birth weight can be used to guide genetic testing (a birth weight $>4.4 \mathrm{~kg}$ is $80 \%$ specific for an HNF4 $\alpha$ mutation compared with an $\mathrm{HNFI} \alpha$ mutation $^{23}$ ) and neonates with hyperinsulinaemia and a family history of diabetes should be tested for an HNF4 $\alpha$ mutation (D grade).

\section{Glucokinase mutations are a common cause of incidental hyperglycaemia, and do not require treatment}

Glucokinase catalyses the first step in glycolysis and is rate limiting. The kinetics of this enzyme make it able to alter flux through glycolysis according to the glucose

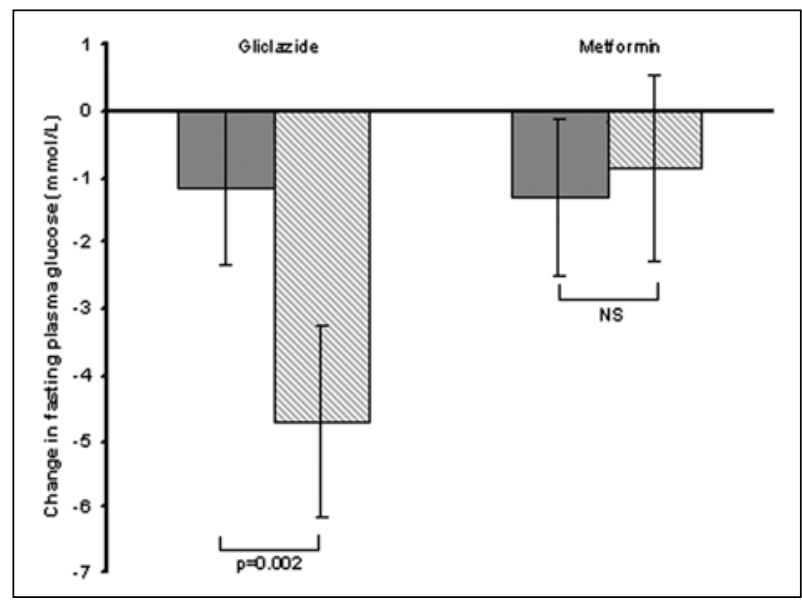

FIGURE 2 Fasting glucose reduction achieved by gliclazide and metformin in patients with HNFI $\alpha$ mutations and patients with type 2 diabetes. ${ }^{18}$ Diagonal shaded bars represent HNFI $\alpha$ patients; solid bars are type 2 diabetic patients. (With kind permission of The Lancet.) 
concentration, and thus it acts as the pancreatic glucose sensor. Heterozygous inactivating mutations in glucokinase cause a shift in the glucose response curve, resulting in patients having a raised fasting glucose. However, given sufficient stimulus, the $\beta$-cell will maximally secrete insulin, and thus the post-prandial glucose rise is small. So classically patients with MODY due to a glucokinase mutation will have a high fasting glucose $(>5.5 \mathrm{mmol} / \mathrm{l})$ but a small increment at 2 hours after a $75 \mathrm{~g}$ oral glucose challenge $(<3.5 \mathrm{mmol} / \mathrm{l})$ (evidence level $2+) .{ }^{24}$ As a result of this ability to respond to meals, the $\mathrm{HbA}_{\mathrm{lc}}$ in patients with glucokinase mutations is usually normal or only slightly elevated, and hence the risk of microvascular disease is low. ${ }^{25}$ Treatment is not indicated, and in fact the use of insulin or oral agents has little impact on glycaemia.

In a Czech study of 60 paediatric patients referred to secondary care with asymptomatic hyperglycaemia who had persistent hyperglycaemia on retesting, 35 (68\%) were found to have glucokinase mutations, two had an HNFI $\alpha$ mutation, one had an HNF4 $\alpha$ mutation and one a Kir6.2 mutation. Eleven had type I diabetes ${ }^{26}$ (evidence level $2+$ ). This study contrasts with a study in an older population, aged 30-70 years, with an increased diabetes risk and with fasting hyperglycaemia $(5.5-7.7 \mathrm{mmol} / \mathrm{l})$, where the prevalence of glucokinase mutations was just $5 / 658$ patients. ${ }^{27}$ Thus in this paediatric population, where the prior probability of finding a monogenic cause is high, there is a higher prevalence of glucokinase mutations, whereas in the older population where type 2 diabetes is much more likely, fasting hyperglycaemia or a small increment at oral glucose tolerance testing are not discriminatory.

\section{TYPE I AND TYPE 2 DIABETES}

After many years with little progress, the acceleration in affordable genotyping technology and advances in our understanding of genetic architecture have prompted a flurry of exciting publications. These report in excess of 20 robustly replicated loci for type 2 diabetes ${ }^{28}$ (evidence level $1++$ ) and 18 for type I diabetes ${ }^{29}$ (evidence level $\mathrm{I++}$. The main output of these discoveries has been that novel pathways have been identified for diabetes, and that there is a considerable overlap between different diseases (e.g. type 2 diabetes and prostate cancer, ${ }^{30}$ type I diabetes, coeliac disease and rheumatoid arthritis $^{31}$. A full discussion of this is beyond the scope of this review).

Considerable effort is under way to translate these genetic findings into an understanding of the biological mechanism. It is likely that the greatest clinical benefit of genetics of common diabetes will be in the development of novel therapies. However, what remains uncertain is the direct clinical utility of genetics of type I and 2 diabetes. While a number of groups have shown that combining all the known type 2 diabetes genes can be used to predict disease, this is of little added value to traditional risk factors such as BMI, age and family history. To assess predictive utility a receiving operating curve (ROC) is usually plotted, where the area under the ROC (AUROC) is a measure of predictive ability ( $50 \%$ being random, $80-85 \%$ the level thought to be clinical useful to predict disease). In a study of two populations (the Botnia study and the Malmö Preventive Project) where longitudinal data was available on the development of diabetes, the AUROC for phenotype alone was 0.74 , and this was only increased to 0.75 $\left(p=1 * 10^{-4}\right)$ by the inclusion of genotype at 16 polymorphisms. ${ }^{32}$ Even in type I diabetes where the sibling relative risk $\left(\lambda_{s}\right)$ is much greater than in type 2 diabetes (I5 vs 3 ), the utility of genetic testing has still to be established. ${ }^{33}$ One problem is that all the loci identified only add up to a small fraction of the heritability of type I or type 2 diabetes. The current hope is that this 'missing heritability' consists of multiple rare variants with large effect, and identifying these may enhance prediction.

Another area of hope where genetics might deliver is in pharmacogenetics of type 2 diabetes, a field that also is accelerating fast. ${ }^{34}$ However, once again, although the discoveries help unravel drug mechanism, they lack clinical utility due to small effect sizes. In a recent study, $6 \%$ of the population who carry two loss-of-function polymorphisms in CYP2C9, encoding the key enzyme that metabolises sulphonylureas, were 3.4 times less likely to achieve a treatment $\mathrm{HbA}_{\mathrm{lc}}$ of $<7 \%$. $^{35}$ This is the largest pharmacogenetic effect described to date for diabetes drugs, yet the added predictive value of genotype was minimal, and there remains considerable unexplained variation in individual response to diabetes drugs - an area where rare variant discovery might contribute. The field where pharmacogenetics is impacting on clinical medicine is in its utility to predict very rare but extremely severe adverse drug reactions, with the paradigm being that of HLA$B * 5701$ and abacavir hypersensitivity. ${ }^{36}$ In diabetes there are not such severe adverse reactions, but the ability to predict metformin intolerance, thiazolidinedione-induced oedema or hypoglycaemia with sulphonylureas is an area where genetics may begin to play a role in the clinic.

\section{PRACTICAL IMPLICATIONS}

\section{Neonatal diabetes}

As $60 \%$ of permanent neonatal diabetes and $26 \%$ of transient neonatal diabetes are due to $\mathrm{K}_{\text {ATP }}$ channel mutations and $90 \%$ of these are able to be treated with sulphonylureas with near normoglycaemia, then:

- All infants, children or adults who develop(ed) diabetes before six months of age should have genetic testing (grade B);

- All infants who have a $K_{\text {ATP }}$ channel gene mutation should be trialled with high-dose sulphonylurea (grade B). 
E Pearson

\section{Clinical suspicion for MODY}

In the absence of other features that would make an alternative diagnosis more likely.

E.g. family history of deafness, acanthosis nigricans, lipoatrophy, retinitis pigmentosa, myotonia, features of secondary diabetes, etc.

High

Diabetes diagnosed before the age of 25 , 3-generation family history of diabetes AND one of MODY-specific phenotype

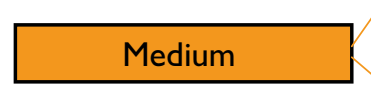

MODY vs type I diabetes
$\geq 2$ generation family history AND

No history of DKA or

MODY-specific phenotype

MODY vs type 2 diabetes

$\geq 2$ generation family history Non-obese, diagnosis before age 40 , Caucasian $\$$ AND either

Absence of features of insulin resistance

MODY-specific phenotypes

HNFI : Sulphonylurea sensitivity, rena glycosuria; HNF4 $\alpha$ : macrosomia, neonatal hypoglycaemia; HNFI $\beta$ renal cystic disease, genital tract malformation; GCK: stable fasting hyperglycaemia with increment at 2 hours after oral glucose $<3.5 \mathrm{mmol} / \mathrm{l}$ e.g. no PCOS, HDL> 1.2
Genetic testing OR a
MODY-specific phenotype No genetic testing Reassess if other family members develop diabetes or other features develop

§ For Asians and other high-risk ethnic groups a lower BMI cut-off should be used.

FIGURE 3 A flow chart depicting an approach to deciding whether to screen for MODY, either by direct genetic testing or by testing C-peptide and pancreatic autoantibodies.

Genetic testing should be carried out before considering a trial of sulphonylureas as high doses of sulphonylurea are often required (doses up to five times the maximal adult dose/kg have been used), and knowing that an individual has a $\mathrm{K}_{\text {ATP }}$ channel mutation will provide confidence in progressing up to such doses before seeing an insulin reduction. Genetic testing for neonatal diabetes is currently free of charge (www.diabetesgenes.org.uk).

Since awareness of neonatal diabetes as a distinct entity has increased, the estimated prevalence has risen and is now estimated at one in 200,000 to 260,000 live births, ${ }^{37}$ suggesting there should be about $15-20$ cases in Scotland, and about $200-250$ in the UK as a whole. A relative lack of adults currently diagnosed suggests that the adult population is a considerable source of undiagnosed neonatal diabetes, and as adults with $\mathrm{K}_{\text {ATP }}$ channel mutations can still successfully transfer off insulin, efforts should be made by adult diabetologists to identify these people within the 'type I' patients in secondary care (grade D).

There is increasing, albeit anecdotal, evidence ${ }^{38}$ that treating early with glibenclamide can reverse or even prevent the neurological features of iDEND, and therefore all children with a confirmed $\mathrm{K}_{\text {ATP }}$ channel mutation should be started on a sulphonylurea as soon as possible, and genetic testing should not be delayed (grade D).

\section{Identifying MODY}

The classical defining MODY criteria are of a three-generation family history, an age of onset in one family member before 25 and non-insulin-requiring diabetes. Sequencing MODY genes should be considered in families who fulfil these criteria, with specific features being used to guide the gene to be sequenced (see Table I). For example:

- $\quad$ Increased birth weight - HNF4 $\alpha$

- Renal glycosuria - HNFI $\alpha$

- Renal cysts - HNFI $\beta$

For further information, please refer to the 'Best practice guidelines for the molecular genetic diagnosis of maturityonset diabetes of the young ${ }^{23}$ or the International Society for Pediatric and Adolescent Diabetes (ISPAD) guidelines for diagnosis and management of monogenic diabetes. ${ }^{39}$

Recommendation: Sequence MODY genes in families that fulfil classic MODY criteria (grade D).

Additional clinical criteria may also suggest MODY in patients who do not fulfil the above criteria. Testing pancreatic autoantibodies and C-peptide can be helpful. A suggested approach to identify MODY in the diabetes clinic is shown in Figure 3.

\section{Pancreatic autoantibodies}

Type I diabetes is defined by the presence of autoimmune destruction of the $\beta$-cells, and this is characterised by 
The practical implications of genetics

detectable pancreatic autoantibodies at diagnosis. A number of autoantibodies can be measured, and if four antibodies are measured (to glutamate decarboxylase, [GAD-65], islet antigen 2 [IA-2], insulin and ZnT8A), only $2-4 \%$ of patients are autoantibody-negative. ${ }^{40}$ Currently both IA-2 and GAD antibody testing is sensitive and specific, although only GAD antibody testing is routinely available. ${ }^{41}$ Where possible, both IA-2 and GAD antibodies should be tested in all individuals presenting with presumed type I diabetes, if only to confirm clinical diagnosis. If these antibodies are present in low titre (negative), an alternative diagnosis such as MODY should be considered, although, particularly if only GAD antibodies were tested, type I diabetes cannot be excluded. It should be emphasised that whatever the ultimate diagnosis, a clinical presentation with ketosis and severe hyperglycaemia requires insulin treatment to reverse the metabolic abnormalities.

\section{Recommendations:}

- Reconsider a diagnosis of type I diabetes if GAD (and IA-2) antibodies are negative (grade D);

- If in doubt, treat with insulin initially as this is safe and effective. Insulin treatment can be withdrawn once a diagnosis is made (grade D).

\section{C-peptide}

The C-peptide is cleaved in proinsulin processing, and is co-secreted with insulin. It is thus a marker of endogenous insulin secretion and is particularly useful when a patient is insulin treated, as the serum insulin assay cannot be used. Five years after diagnosis of type I diabetes in the Diabetes Control and Complications Trial, $0 \%$ of adolescents and only II\% of adults had measurable C-peptide (evidence level $2+) .{ }^{42}$ So if MODY is queried more than five years after diagnosis of 'type I diabetes', the persistence of C-peptide makes a diagnosis of type I diabetes unlikely and other causes should be considered. C-peptide needs to reach the laboratory within one hour and thus is not suitable for primary care; however, urinary C-peptide is stable and the urinary C-peptide-creatinine ratio may prove to be useful ${ }^{43}$ but is not yet routinely available.

Recommendation: In patients where non-type I diabetes is suspected over five years from diagnosis, measure C-peptide (when glucose $>8 \mathrm{mmol} / \mathrm{l}$ ). Persistence of $\mathrm{C}$-peptide after five years of diabetes makes type I diabetes unlikely (grade D).

\section{Incidental hyperglycaemia}

As highlighted above, $68 \%$ of children selected purely on persistent asymptomatic hyperglycaemia had a glucokinase mutation, yet family history of diabetes was not an inclusion criterion for glucokinase sequencing.

Recommendation: Asymptomatic hyperglycaemia that does not progress in children and young adults should prompt sequencing for glucokinase mutations (grade $\mathrm{C}$ ).

\section{Treatment choice}

Recommendations:

- $\quad$ Patients with an HNFI $\alpha$ mutation should be treated with a low-dose sulphonylurea first line (grade A);

- Patients with and HNF4 $\alpha$ mutation should be treated with a low-dose sulphonylurea first line (grade D);

- Patients with a glucokinase mutation do not require treatment (grade D).

\section{Prevalence of MODY and availability of testing}

There is considerable variation in the number of MODY patients by region in the UK. All data that follow are provided by the Exeter referral lab (Shields, Hattersley, Ellard; personal communication). The highest number of MODY patients is seen in the southwest of England, with a prevalence of 49 per million population. This is likely to reflect the strong research and clinical interest in MODY based in Exeter. Beyond this there is a clear difference in number by country, with Scotland having the highest number of MODY patients per population (27 per million). England has 20 per million, Wales 13 per million and Northern Ireland 5 per million (evidence level 3). There are two probable explanations for this. Firstly, in an initiative set up by the Exeter team, 18 diabetes specialist nurses received additional training on genetic forms of diabetes with an aim to increase and update the knowledge of the local diabetes teams. These Genetic Diabetes Nurses were originally funded within England and Scotland but not in Wales or Northern Ireland. Another barrier to referral for genetic testing is cost and specifically which budget is used to meet these costs. Some primary care trusts have not agreed to meet these costs in England. In Scotland, with the highest referral rate and highest number of MODY patients identified, the cost for genetic testing is met centrally.

Recommendation: Increased awareness and reduced barriers to genetic testing increase detection of MODY. All patients should have similar access to genetic testing irrespective of their geographical location in the UK (grade D).

\section{SUMMARY}

In the past five years there have been considerable developments in diabetes genetics. In type I and type 2 diabetes the exciting new discoveries are shedding new light on biological mechanisms of disease, but have yet to impact directly on clinical care. In monogenic diabetes the progress has been in translating the genetic discoveries into clinical care, and establishing that knowing the genetic aetiology of diabetes determines the treatment choice. With this established, the critical next step is to fully incorporate genetic testing into routine care. 
E Pearson

\section{REFERENCES}

I lafusco D, Stazi MA, Cotichini R et al. Permanent diabetes mellitus in the first year of life. Diabetologia 2002; 45:798-804. doi: I0.1007/ s00125-002-0837-2

2 Edghill EL, Dix RJ, Flanagan SE et al. HLA genotyping supports a nonautoimmune etiology in patients diagnosed with diabetes under the age of 6 months. Diabetes 2006; 55:1895-8. doi:|0.2337/ db06-0094

3 Shield JP. Understanding neonatal diabetes mellitus. J Pediatr 2002; |41:462-3. doi: I0.1067/mpd.2002.128032

4 Flanagan SE, Patch AM, Mackay DJ et al. Mutations in ATP-sensitive $\mathrm{K}+$ channel genes cause transient neonatal diabetes and permanent diabetes in childhood or adulthood. Diabetes 2007; 56:1930-7. doi: $10.2337 / \mathrm{db} 07-0043$

5 Edghill EL, Flanagan SE, Patch AM et al. Insulin mutation screening in I,044 patients with diabetes: mutations in the INS gene are a common cause of neonatal diabetes but a rare cause of diabetes diagnosed in childhood or adulthood. Diabetes 2008; 57:1034-42. doi: I0.2337/db07-I405

6 Gloyn AL, Pearson ER, Antcliff JF et al. Activating mutations in the gene encoding the ATP-sensitive potassium-channel subunit Kir6.2 and permanent neonatal diabetes. N Engl J Med 2004; 350:183849. doi:I0.I056/NEJMoa032922

7 Njølstad PR, Søvik O, Cuesta-Muñoz A et al. Neonatal diabetes mellitus due to complete glucokinase deficiency. $N$ Engl J Med 200I; 344:I 588-92. doi:I0.1056/NEJM200I05243442 I04

8 Shield JP. Neonatal diabetes: how research unravelling the genetic puzzle has both widened our understanding of pancreatic development whilst improving children's quality of life. Hormone Res 2007; 67:77-83. doi:I0.II59/000096354

9 Darendeliler F, Fournet JC, Bas F et al. ABCC8 (SURI) and KCNJII (KIR6.2) mutations in persistent hyperinsulinemic hypoglycemia of infancy and evaluation of different therapeutic measures. J Pediatr Endocrinol Metab 2002; 15:993-1000.

10 Babenko AP, Polak $\mathrm{M}$, Cave $\mathrm{H}$ et al. Activating mutations in the ABCC8 gene in neonatal diabetes mellitus. N Engl J Med 2006; 355:456-66. doi:10.1056/NEJMoa055068

II Proks P, Arnold AL, Bruining J et al. A heterozygous activating mutation in the sulphonylurea receptor SURI (ABCC8) causes neonatal diabetes. Hum Mol Genet 2006; I 5: I793-800. doi:I0.1093/ hmg/ddllol

I2 Pearson ER, Flechtner I, Njolstad PR et al. Switching from insulin to oral sulfonylureas in patients with diabetes due to Kir6.2 mutations. N Engl J Med 2006; 355:467-77. doi: I0.1056/NEJMoa06I759

I 3 Sagen JV, Raeder H, Hathout E et al. Permanent neonatal diabetes due to mutations in KCNJI I encoding Kir6.2:patient characteristics and initial response to sulfonylurea therapy. Diabetes 2004; 53:27/3-8. doi: I0.2337/diabetes.53.I0.27I3

14 Stride A, Hattersley AT. Different genes, different diabetes: lessons from maturity-onset diabetes of the young. Ann Med 2002; 34:207-16.

15 Søvik O, Njølstad P, Folling I et al. Hyperexcitability to sulphonylurea in MODY3. Diabetologia 1998; 4I:607-8. doi:I0.1007/s00 I 250050956

16 Hansen T, Eiberg H, Rouard M et al. Novel MODY3 mutations in the hepatocyte nuclear factor-lalpha gene: evidence for a hyperexcitability of pancreatic beta-cells to intravenous secretagogues in a glucose-tolerant carrier of a P447L mutation. Diabetes 1997; 46:726-30. doi:10.2337/diabetes.46.4.726

17 Pearson ER, Liddell WG, Shepherd $M$ et al. Sensitivity to sulphonylureas in patients with hepatocyte nuclear factor-lalpha gene mutations: evidence for pharmacogenetics in diabetes. Diabet Med 2000; 17:543-5. doi:I0.1046/j. I464-549I.2000.00305.x

I8 Pearson ER, Starkey BJ, Powell RJ et al. Genetic cause of hyperglycaemia and response to treatment in diabetes. Lancet 2003; 362:|275-8I. doi:I0.I0I6/S0|40-6736(03) |457|-0

19 Pearson ER, Pruhova S, Tack CJ et al. Molecular genetics and phenotypic characteristics of MODY caused by hepatocyte nuclear factor 4alpha mutations in a large European collection. Diabetologia 2005; 48:878-85. doi: I0.1007/s00 I 25-005-I738-y
20 Shepherd M, Shields B, Ellard S et al. A genetic diagnosis of HNFIA diabetes alters treatment and improves glycaemic control in the majority of insulin-treated patients. Diabet Med 2009; 26:437-4I. doi: I0. I I I I/j. |464-549I.2009.02690.x

2I Hermann LS, Schersten B, Bitzen PO et al.Therapeutic comparison of metformin and sulfonylurea, alone and in various combinations. A double-blind controlled study. Diabetes Care 1994; 17:1 100-9. doi:10.2337/diacare.17.10.1100

22 Pearson ER, Boj SF, Steele AM et al. Macrosomia and hyperinsulinaemic hypoglycaemia in patients with heterozygous mutations in the HNF4A gene.PLoS Med 2007; 4: I I 8. doi: I0.137I/ journal.pmed.0040I I8

23 Ellard S, Bellanne-Chantelot C, Hattersley AT. Best practice guidelines for the molecular genetic diagnosis of maturity-onset diabetes of the young. Diabetologia 2008; 51:546-53. doi:10.1007/ s00I25-008-0942-y

24 Stride A,Vaxillaire M, Tuomi T et al. The genetic abnormality in the beta cell determines the response to an oral glucose load. Diabetologia 2002; 45:427-35. doi: 10.1007/s00 I 25-00I-0770-9

25 Velho G, Hattersley AT, Froguel P. Maternal diabetes alters birth weight in glucokinase-deficient (MODY2) kindred but has no influence on adult weight, height, insulin secretion or insulin sensitivity. Diabetologia 2000; 43:1060-3. doi:10.1007/ s00I25005I490

26 Feigerlova E,Pruhova S, Dittertova L et al. Aetiological heterogeneity of asymptomatic hyperglycaemia in children and adolescents. Eur J Pediatr 2006; 165:446-52. doi:10.1007/s00431-006-0106-3

27 Gloyn AL, van de Bunt M, Stratton IM et al. Prevalence of GCK mutations in individuals screened for fasting hyperglycaemia. Diabetologia 2009; 52:172-4. doi:I0.1007/s00 I25-008-II88-4

$28 \mathrm{McCarthy}$ MI.What will genome-wide association studies mean to the clinical endocrinologist? J Clin Endocrinol Metab 2009; 94:22456. doi:10.1210/jc.2009-0403

29 Barrett JC, Clayton DG, Concannon P et al. Genome-wide association study and meta-analysis find that over 40 loci affect risk of type I diabetes. Nat Genet 2009; May 10. [Epub ahead of print]

30 Frayling TM, Colhoun H, Florez JC. A genetic link between type 2 diabetes and prostate cancer. Diabetologia 2008; 5I:1757-60. doi:I0.1007/s00I25-008-III4-9

3I Heap GA, van Heel DA. The genetics of chronic inflammatory diseases. Hum Mol Genet 2009; I8(RI):RI0I-6. doi:I0.I093/hmg/ ddp001

32 Lyssenko V, Jonsson A, Almgren $P$ et al. Clinical risk factors, DNA variants, and the development of type 2 diabetes. $N$ Engl J Med 2008; 359:2220-32. doi:10.1056/NEJMoa080I869

33 Clayton DG. Prediction and interaction in complex disease genetics: experience in type I diabetes. PLoS Genet 2009; 5:el 000540. doi: I0.137I/journal.pgen. I000540

34 Pearson ER. Pharmacogenetics in diabetes. Curr Diab Rep 2009; 9: I72-8I. doi: I0.1007/s | |892-009-0028-3

35 Zhou K, Donnelly L, Burch L et al. Loss-of-function CYP2C9 variants improve therapeutic response to sulfonylureas in type 2 diabetes: a Go-DARTS study. Clin Pharmacol Ther 2010; 87:52-6. doi: 10.1038/clpt.2009.176

36 Mallal S, Phillips E, Carosi G et al. HLA-B*570I screening for hypersensitivity to abacavir. N Engl J Med 2008; 358:568-79. doi: I0.1056/NEJMoa0706I35

37 Slingerland AS, Shields BM, Flanagan SE et al. Referral rates for diagnostic testing support an incidence of permanent neonatal diabetes in three European countries of at least I in 260,000 live births. Diabetologia 2009; 52:1683-5. doi:10.1007/s00I25-009. 1416-6

38 Slingerland AS, Hurkx W, Noordam K et al. Sulphonylurea therapy improves cognition in a patient with the V59M KCNJII mutation. Diabet Med 2008;25:277-8I. doi: I 0. I I I I/j. I464-549I.2007.02373.x 
The practical implications of genetics

39 HattersleyA, Bruining J, Shield J et al.The diagnosis and management of monogenic diabetes in children and adolescents. Pediatr Diabetes 2009; I0(SuppI I2):33-42. doi: I 0. I I I /j. I399-5448.2009.0057I.x

40 Verge CF, Howard NJ, Rowley MJ et al. Anti-glutamate decarboxylase and other antibodies at the onset of childhood IDDM: a population-based study.Diabetologia 1994;37: I I I3-20.doi: I0.1007/ BF004I8375

41 Bingley PJ. Clinical applications of diabetes antibody testing. J Clin Endocrinol Metab 2010; 95:25-33. doi:I0.1210/jc.2009-1365

42 Effects of age, duration and treatment of insulin-dependent diabetes mellitus on residual beta-cell function: observations during eligibility testing for the Diabetes Control and Complications Trial (DCCT). The DCCT Research Group.J Clin Endocrinol Metab 1987; 65:30-6. doi: I0.1210/jcem-65-I-30
43 McDonald T], Knight BA, Shields BM et al. Stability and reproducibility of a single-sample urinary $\mathrm{C}$-peptide/creatinine ratio and its correlation with 24-h urinary C-peptide. Clin Chem 2009; 55:2035-9. doi:10.1373/clinchem.2009.129312

44 Bingham C, Hattersley AT. Renal cysts and diabetes syndrome resulting from mutations in hepatocyte nuclear factor-lbeta. Nephrol Dial Transplant 2004; 19:2703-8. doi:I0.1093/ndt/gfh348 